\title{
Effect of Annealing Atmosphere on the Diode Behaviour of $\mathrm{ZnO} / \mathrm{Si}$ Heterojunction
}

\author{
Sadia Muniza Faraz ${ }^{1,}$, Syed Riaz un Nabi Jafri ${ }^{1}$, Zarreen Tajvar ${ }^{1}$, Naveed ul Hassan Alvi ${ }^{2}$, \\ Qamar-ul-Wahab ${ }^{3}$, Omer Nur $^{4}$ \\ ${ }^{1}$ Department of Electronic Engineering, NED University of Engineering and Technology, \\ 75270 Karachi, Pakistan \\ ${ }^{2}$ RISE Research Institutes of Sweden, \\ Bredgatan 33, Norrkoping, Sweden \\ ${ }^{3}$ Departments of Physics, Chemistry and Biology (IFM), Linkoping University, \\ Linkoping, Sweden \\ ${ }^{4}$ Department of Science and Technology (ITN), Faculty of Science \& Engineering, \\ Linkoping University, \\ Linkoping, Sweden \\ smuniza@neduet.edu.pk
}

\begin{abstract}
The effect of thermal annealing atmosphere on the electrical characteristics of Zinc oxide ( $\mathrm{ZnO}$ ) nanorods/pSilicon (Si) diodes is investigated. $\mathrm{ZnO}$ nanorods are grown by low-temperature aqueous solution growth method and annealed in Nitrogen and Oxygen atmosphere. As-grown and annealed nanorods are studied by scanning electron microscopy (SEM) and photoluminescence (PL) spectroscopy. Electrical characteristics of $\mathrm{ZnO} / \mathrm{Si}$ heterojunction diodes are studied by current-voltage (I-V) and capacitance-voltage (C-V) measurements at room temperature. Improvements in rectifying behaviour, ideality factor, carrier concentration, and series resistance are observed after annealing. The ideality factor of 4.4 for as-grown improved to 3.8 and for Nitrogen and Oxygen annealed improved to 3.5 nanorods diodes. The series resistances decreased from 1.6 to 1.8 times after annealing. An overall improved behaviour is observed for oxygen annealed heterojunction diodes. The study suggests that by controlling the $\mathrm{ZnO}$ nanorods annealing temperatures and atmospheres the electronic and optoelectronic properties of $\mathrm{ZnO}$ devices can be improved.
\end{abstract}

Index Terms- $\mathrm{ZnO}$ annealing; Heterojunction; Series resistance; $\mathrm{ZnO}$ nanorods.

\section{INTRODUCTION}

Zinc oxide $(\mathrm{ZnO})$ is a direct and wideband gap $(3.37 \mathrm{eV})$ semiconductor with large exciton binding energy $(60 \mathrm{meV})$. Its electronic and optoelectronic devices, such as light emitting diodes, sensors, thin film transistors, solar cells, and UV photo detectors, are widely studied [1]-[4].

$\mathrm{ZnO}$ is intrinsically n-type and obtaining p-type conductivity by growing high-quality $\mathrm{p}-\mathrm{ZnO}$ is very difficult. For this reason, $\mathrm{ZnO}$ based $\mathrm{p}$-n heterojunctions $(\mathrm{HJ})$ are realized on a variety of substrates like $\mathrm{Si}, \mathrm{GaN}$, $\mathrm{SiC}, \mathrm{CuO} 2$, etc. [5]-[8]. The heterojunctions of $\mathrm{ZnO}$ nanorods/Si have attracted a great deal of interest due to their cost effective fabrication processes. Unfortunately,

Manuscript received 16 February, 2021; accepted 3 June, 2021. their electronic and optical properties are strongly influenced by the presence of point defects and strains contained in nanorods. Therefore, the growth of $\mathrm{ZnO}$ nanorods (NRs) with better optical quality is very important for the realization of efficient Nano devices [9]. Thermal treatment is a conventional and effective technique that can change the properties of nanorods by reducing strains and defects hence improving crystalline quality [10]-[13].

Annealing at different temperatures and atmospheres removes impurities and structural defects from the crystal lattice and improves the electronic and optoelectronic properties of $\mathrm{ZnO}$ devices. The concentration of intrinsic defects and defect levels may be varied by varying the annealing atmosphere. The intrinsic defects, such as oxygen vacancies, may also be reduced by high temperature annealing in $\mathrm{O}_{2}$ or Argon (Ar) [11]. Therefore, electrical and optical properties of $\mathrm{ZnO} / \mathrm{Si}$ heterojunction may be modulated by controlling the $\mathrm{ZnO}$ nanorods growth temperature, annealing temperature, and atmosphere [9], [14].

In a recent study, a reduction in native defects at the surface is reported for $\mathrm{ZnO}$ nanoparticles annealed at various temperatures [15]. Similarly, significant improvements in ideality factor, rectification ratio, and reverse breakdown voltage are observed in $\mathrm{ZnO} / \mathrm{Si}$ heterojunctions annealed in Nitrogen $\left(\mathrm{N}_{2}\right)$ atmosphere [10], [16]. Furthermore, better rectification is achieved for $\mathrm{ZnO}$ Schottky diode with seed layer pre-annealed in $\mathrm{N}_{2}$ [17]. The interface between the $\mathrm{ZnO} \mathrm{NRs}$ and $\mathrm{Si}$ is reported to be improved after annealing in Oxygen $\left(\mathrm{O}_{2}\right)$. Decreased reverse current and improved rectification are observed for diodes of $\mathrm{O}_{2}$ annealed nanorods [13]. Similarly, a substantial enhancement in optical and structural properties is seen after annealing in $\mathrm{Ar}$ and $\mathrm{O}_{2}$ atmospheres [18]. Y. Tu et al. have reported optimized performance with increased carrier concentration observed in $\mathrm{ZnO}$ nanorods diodes with hydrothermal seed layer pre-annealed in various 
atmospheres [12]. Likewise, improved diode performance is observed for $\mathrm{ZnO}$ nanorods annealed at $450{ }^{\circ} \mathrm{C}$ and under different annealing conditions [15], [19].

In the present study, $\mathrm{ZnO}$ nanorods are grown on $\mathrm{p}-\mathrm{Si}$ substrate by aqueous chemical growth technique (ACG). Post growth thermal annealing of $\mathrm{ZnO}$ nanorods is done at $400{ }^{\circ} \mathrm{C}$ in $\mathrm{O}_{2}$ and $\mathrm{N}_{2}$ atmosphere. Structural characteristics are studied with scanning electron microscopy (SEM) and photoluminescence (PL) spectroscopy. Electrical characteristics are studied by current-voltage (I-V) and capacitance-voltage $(\mathrm{C}-\mathrm{V})$ measurements. The effects of thermal annealing atmospheres on various diode parameters, such as rectification factor, ideality factor, and series resistance, are discussed.

\section{MATERIALS AND METHODS}

$\mathrm{ZnO}$ nanorods were grown on $\mathrm{p}-\mathrm{Si}$ substrate by aqueous chemical growth (ACG) method [20], [21]. The seed solution, prepared by diluting zinc acetate dehydrate in methanol, was spin coated on the substrate three times and then heated at $250{ }^{\circ} \mathrm{C}$ in air for 20 minutes. The growth solution was prepared with hexamethylenetetramine (HMT) $\left(\mathrm{C}_{6} \mathrm{H}_{12} \mathrm{~N}_{4}\right)$ and zinc nitrate $\left(\mathrm{Zn}\left(\mathrm{NO}_{3}\right) 26 \mathrm{H}_{2} \mathrm{O}\right) 0.022 \mathrm{mM}-$ $0.075 \mathrm{mM}$, by dissolving in $200 \mathrm{ml}$ of de-ionized water at room temperature. The samples were dipped in the solution and heated for 4 hours at a temperature of $95{ }^{\circ} \mathrm{C}$. After growth, the samples were washed with de-ionized water and blown dried with Nitrogen. The samples were then annealed in Nitrogen and Oxygen atmosphere at $400{ }^{\circ} \mathrm{C}$ for 30 minutes. Before making the ohmic contacts to the heterojunction, an insulating layer of Poly Methyl Methacrylate (PMMA) was spin coated on the samples. Excess PMMA was removed from the top of the nanorods by oxygen plasma cleaning. Aluminium/Platinum $(\mathrm{Al} / \mathrm{Pt})$ ohmic contacts of $50 \mathrm{~nm} / 60 \mathrm{~nm}$ thickness were evaporated on $\mathrm{ZnO}$ nanorods. Aluminium (Al) ohmic contacts of $150 \mathrm{~nm}$ thickness were evaporated on $\mathrm{p}$-Si substrate. The Area of the circular ohmic contact was $10.56 \times 10^{-3} \mathrm{~cm}^{2}$. The Step by step growth process of nanorods is shown in Fig. 1.

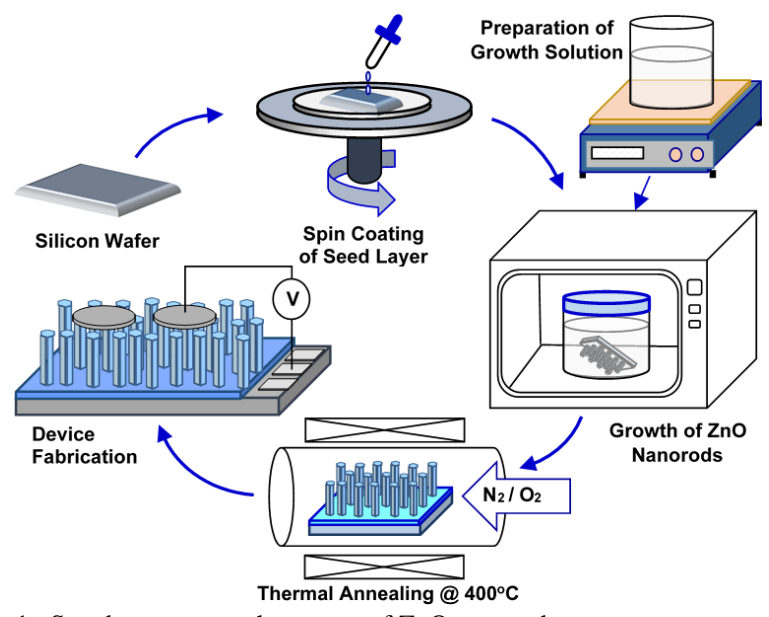

Fig. 1. Step by step growth process of $\mathrm{ZnO}$ nanorods.

The structures of $\mathrm{ZnO}$ nanorods were studied by JEOLJSM - 6301F scanning electron microscope (SEM). Photoluminescence (PL) spectroscopy was done at room temperature using laser lines of wavelength $270 \mathrm{~nm}$ or $350 \mathrm{~nm}$ from an Ar+ laser as the excitation sources. Current-voltage (I-V) and capacitance-voltage (C-V) measurements were performed by using Keithley SCS-4200 semiconductor characterization System.

\section{RESUlTS AND DisCUSSION}

The morphology of nanorods was studied by scanning electron microscopy (SEM). Vertically aligned hexagonal nanorods with almost uniform distribution were revealed as shown in Fig. 2. The approximate height of nanorods was $1.2 \mu \mathrm{m}$ with a mean diameter of $100 \mathrm{~nm}-150 \mathrm{~nm}$. No significant change was observed in the morphology of nanorods after thermal treatment [19], [22].

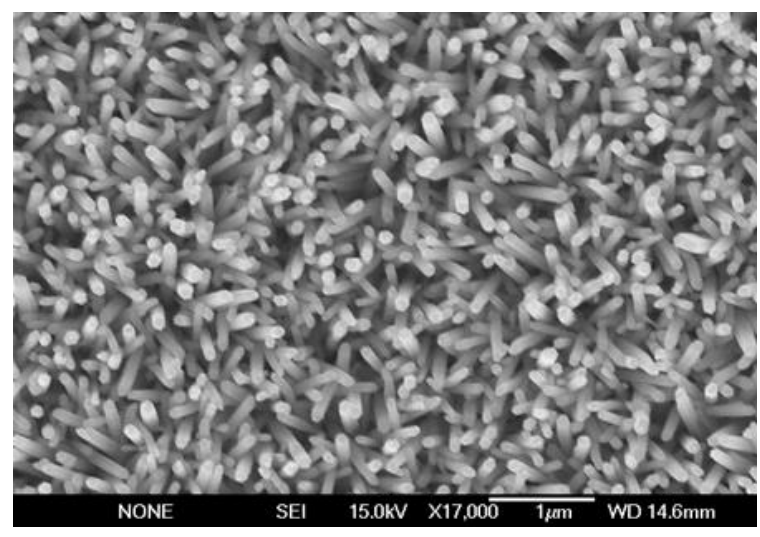

(a)

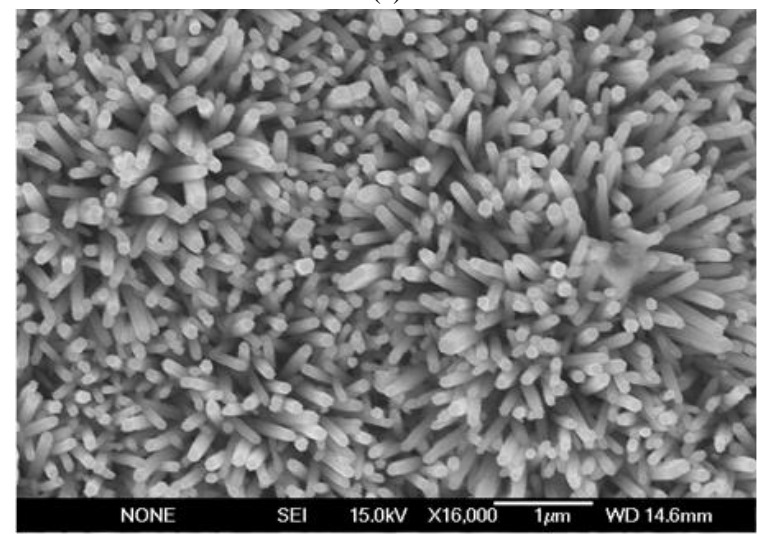

(b)

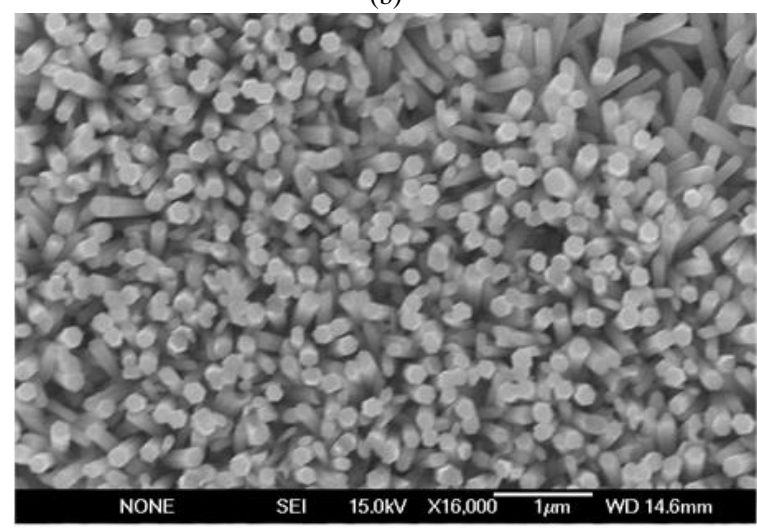

(c)

Fig. 2. SEM images of $\mathrm{ZnO}$ Nanorods: (a) as-grown, (b) $\mathrm{N}_{2}$ annealed, and (c) $\mathrm{O}_{2}$ annealed.

Photoluminescence (PL) spectroscopy was done at room temperature to study the optical properties of nanorods. Two emission peaks were seen in the PL spectra of all the 
samples as shown in Fig. 3. Sharp and strong peaks centered at wavelengths between $376 \mathrm{~nm}$ and $380 \mathrm{~nm}$ and weak broad peaks centered between $535 \mathrm{~nm}$ and $570 \mathrm{~nm}$ were observed. The sharp peaks below the wavelengths of $380 \mathrm{~nm}$ are due to the intrinsic band gap emission, referred as near band emission (NBE) or ultraviolet (UV) emission. This emission is originated due to the recombination of freeexciton across the band gap and due to zinc interstitials [23], [24]. The broad peaks centered between $535 \mathrm{~nm}$ and $570 \mathrm{~nm}$ are due to visible (VIS) emission or deep level emission (DLE). An overall improvement in NBE and DLE emission intensity has been observed. The PL intensity ratio IUV/IDLE depicts an overall improvement in optical properties of $\mathrm{ZnO}$ nanorods after annealing in $\mathrm{O}_{2}$ and $\mathrm{N}_{2}$ as shown in the inset of Fig. 3. The enhancement in NBE indicates the improvement in the crystallinity and reduction in recombination traps. However, weak DLE observed for $\mathrm{O}_{2}$ than $\mathrm{N}_{2}$ annealed sample might be due decrease in oxygen vacancies attributed to the adsorption of oxygen during annealing process [12].

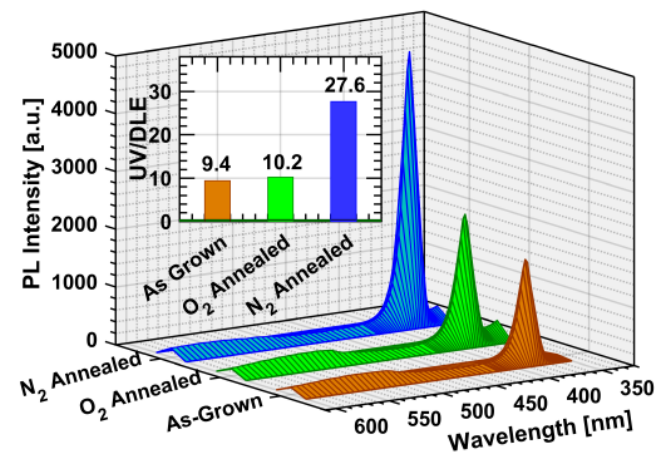

Fig. 3. PL spectra of as-grown, $\mathrm{O}_{2}$ and $\mathrm{N}_{2}$ annealed $\mathrm{ZnO}$ nanorods, inset is the UV/DLE peaks ratio.

Current-voltage (I-V) characteristics of $\mathrm{ZnO} / \mathrm{Si} \mathrm{HJ}$ diodes fabricated from as-grown, $\mathrm{N}_{2}$ and $\mathrm{O}_{2}$ annealed nanorods were measured at bias voltages from $-8 \mathrm{~V}$ to $+8 \mathrm{~V}$. Currentvoltage characteristics are shown in Fig. 4. All HJ diodes exhibited nonlinear rectifying behaviour with improvement in rectification factors $\left(\mathrm{I}_{\mathrm{F}} / \mathrm{I}_{\mathrm{R}}\right)$ from 23 (as-grown) to 40. 1 and 231.2 at $\pm 5 \mathrm{~V}$ for $\mathrm{N}_{2}$ and $\mathrm{O}_{2}$ annealed NRs diodes, respectively. The highest rectification ratio for $\mathrm{O}_{2}$ annealed diodes indicates that the interface between $\mathrm{ZnO}$ and $\mathrm{Si}$ is improved after annealing in $\mathrm{O}_{2}$.

The ideality factor $(n)$ and barrier heights $\left(\varphi_{B}\right)$ were extracted by using (1) and (2):

$$
\begin{gathered}
n=\frac{V}{k T / q}\left[\frac{1}{\ln \left(I / I_{o}+1\right)}\right], \\
\varphi_{B}=-\frac{k T}{q} \ln \frac{I_{o}}{A A^{*} T^{2}} .
\end{gathered}
$$

Here, $\mathrm{k}$ is the Boltzmann's constant, $\mathrm{I}_{\mathrm{o}}$ is the saturation current, $\mathrm{A}$ is the area, and $\mathrm{A}^{*}$ is the Richardson constant $\left(32 \mathrm{~A} / \mathrm{cm}^{2} \mathrm{~K}^{2}\right)$ for $\mathrm{n}-\mathrm{ZnO}$ [21]. The ideality factors decreased from 4.4 (As-Grown) to 3.87 and 3.52 for $\mathrm{N}_{2}$ and $\mathrm{O}_{2}$ annealed $\mathrm{HJ}$ diodes. Decrease in ideality factors of $\mathrm{HJ}$ diodes is often observed after annealing [25]. The obtained barrier heights were $0.74 \mathrm{eV}, 0.74 \mathrm{eV}$, and $0.67 \mathrm{eV}$ for as- grown, $\mathrm{N}_{2}$ and $\mathrm{O}_{2}$ annealed nanorods diodes, respectively.

Charge transport behaviour has been studied from Log ILog V characteristics. Three slopes corresponding to different conduction mechanisms were observed for each diode as shown in Fig. 5. For low voltage Region-I (< $0.8 \mathrm{~V})$, the current increased linearly $(\mathrm{I} \alpha \mathrm{V})$ confirming ohmic transport as the dominant conduction mechanism. For moderate voltage range $(0.8 \mathrm{~V}<\mathrm{V}<3 \mathrm{~V})$, the current increased exponentially $\left(\mathrm{I} \alpha \mathrm{e}^{\mathrm{mV}}\right)$ in as-grown and $\mathrm{N}_{2}$ annealed HJ diodes. This exponential increase indicate that the charge transport is subjected to the space-charge-effect. The current followed power law $\left(\mathrm{I} \alpha \mathrm{V}^{\mathrm{m}}\right)$ in $\mathrm{O}_{2}$ annealed diode. The diode behaviour is dominated by Region-II in all diodes and the current increased due to increased injection of access carriers after filling the deep traps in the band. At higher biasing voltages $(\mathrm{V}>3 \mathrm{~V})$ the Log I-Log V followed the power law $\left(\mathrm{I} \alpha \mathrm{V}^{\mathrm{m}}\right)$ dependence as shown in Region-III in Fig. 5. At higher voltages, when most of the traps are being occupied by injected carriers and carrier transport approaches the trap-filled limit, then further injection of carriers is hindered by the accumulated space charges.

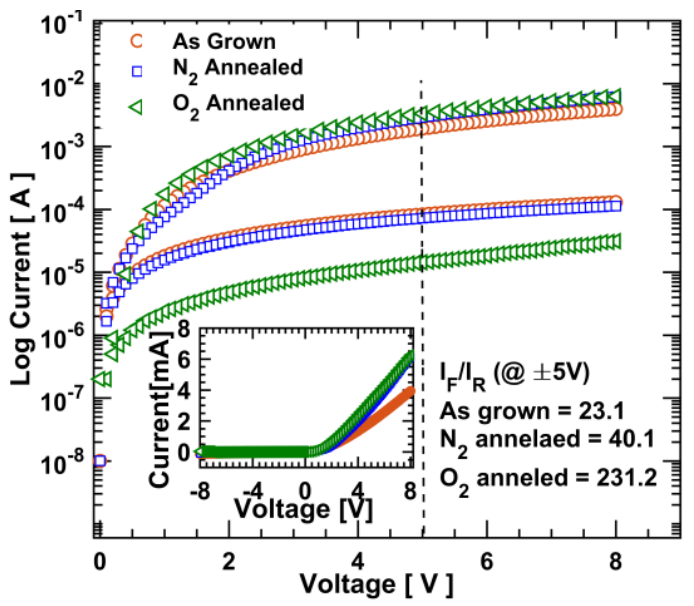

Fig. 4. Current-voltage characteristics of $\mathrm{ZnO} / \mathrm{Si}$ heterojunctions, inset are the IV characteristics on linear scale.

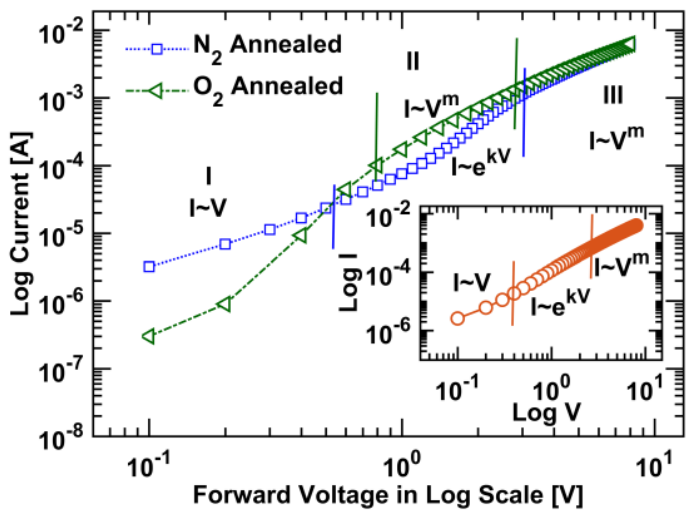

Fig. 5. Log I-Log $\mathrm{V}$ characteristics of $\mathrm{ZnO} / \mathrm{Si}$ heterojunction diodes.

This behaviour may be attributed to the presence of oxygen vacancies [26], [27]. The oxygen-defect-induced carrier density is one of the factors leading to the improved rectification of the diodes when annealed in $\mathrm{N}_{2}$ and $\mathrm{O}_{2}$ [12]. In fact, intrinsic oxygen vacancy-related defects are increased by annealing and we obtain high carrier concentration nanorods, which can lead to improved diode performance. 
The junction capacitance increased annealing as shown in the capacitance-voltage $(\mathrm{C}-\mathrm{V})$ characteristics measured at the frequency of $1 \mathrm{MHz}$ at room temperature in Fig. 6(a). This increase in capacitance may be attributed to the change in depletion region width and carrier concentration due to annealing [10].

The carrier concentrations $\left(\mathrm{N}_{\mathrm{d}}\right)$ were extracted from the slope of the linear segment of the curve shown in Fig. 6(b) by using (3)

$$
\frac{d V}{d\left(A^{2} / C^{2}\right)}=\frac{2}{q \varepsilon_{S} \varepsilon_{o}} \times \frac{1}{N_{d}} .
$$

Here, $\varepsilon_{S}$ is the relative permittivity of $\mathrm{ZnO}$ having a value of 8.2. The carrier concentrations increased from $7.06 \times 10^{12}$ (as-grown) to $9.4 \times 10^{12}$ and $1.25 \times 10^{13} / \mathrm{cm}^{3}$ for $\mathrm{O}_{2}$ and $\mathrm{N}_{2}$ annealed nanorods. For $\mathrm{ZnO}$, this unintentional n-type doping is attributed to oxygen vacancies which act as donor like native point defects. The improvement in $N_{d}$ might be due to the creation of $\mathrm{Zn}$ interstitial related donor type defects and increased hydrogen concentration due to annealing [28], [29]. The built in potentials obtained from Fig. 6(b) are $1.0 \mathrm{~V}, 1.2 \mathrm{~V}$, and $0.8 \mathrm{~V}$ for as-grown, $\mathrm{N}_{2}$ and $\mathrm{O}_{2}$ annealed heterojunctions, respectively.

At high forward voltages, the I-V characteristics of heterojunctions follow power law as shown in Region-III in Fig. 5. This deviation from linearity is due to the presence of interface states and series resistance. The high values of ideality factor are also attributed to barrier inhomogeneity, series resistance, and defects at the junction. Series resistance is an important parameter which plays a crucial role and affects the device behaviour.

The effect of the annealing atmosphere on series resistance has been investigated. Series resistance has been extracted by the method proposed by Chueng [20], [30] given by (4)

$$
\frac{d V}{d(\ln I)}=R_{S} I+\frac{n k T}{q} .
$$

Series resistance and ideality factor are obtained from the linear fitting of the curve of $\mathrm{dV} / \mathrm{d}(\operatorname{lnI})$ vs. current as shown in Fig. 7(a). Furthermore, the series resistance and barrier height are extracted by using (5) and (6):

$$
\begin{gathered}
H(I)=V-\left(\frac{n k T}{q}\right) \ln \left(\frac{I}{A A^{*} T^{2}}\right), \\
H(I)=I R_{S}+n \varphi_{B} .
\end{gathered}
$$

Series resistances and barrier heights are obtained from the slope of the H(I) vs. current plots as shown in Fig. 7(b). It can be seen that the values of series resistance obtained from direct method $(\Delta \mathrm{V} / \Delta \mathrm{I})$ and Chueng's method are in close agreement with each other as listed in Table I and shown in Fig. 8. It is also observed that series resistances decreased after annealing and lowest values of series resistances are obtained for diodes annealed in $\mathrm{O}_{2}$ atmosphere. This decrease in series resistance often observed after annealing is sometimes attributed to excess zinc contents or higher level of oxygen vacancies [31]-[33].

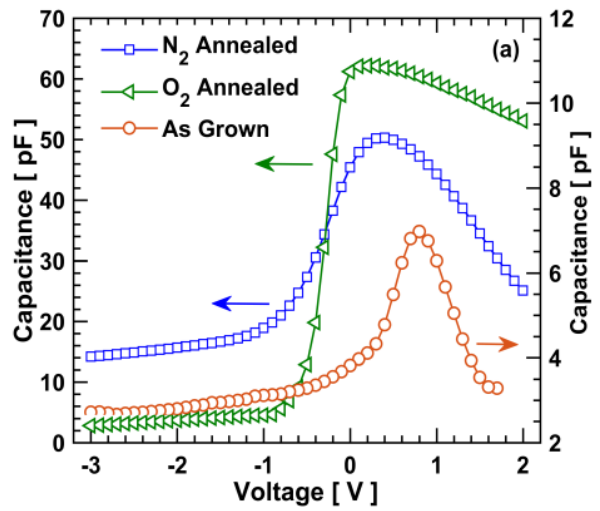

(a)

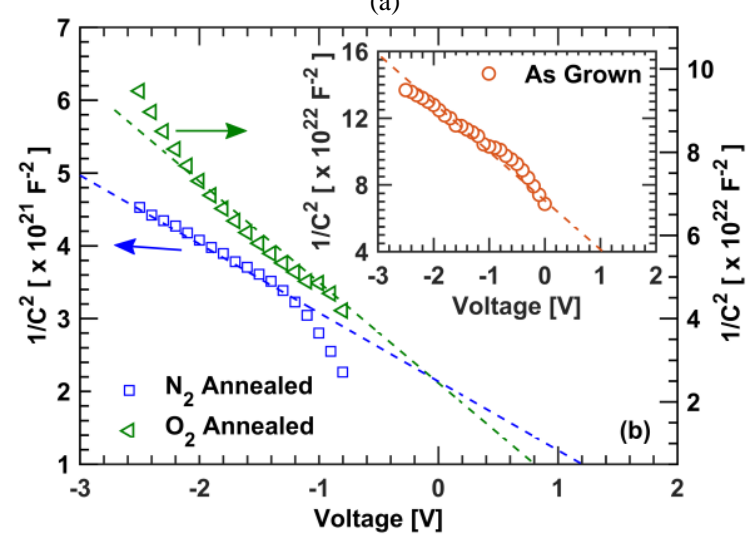

(b)

Fig. 6. (a) Capacitance-voltage (C-V) characteristics; (b) $1 / \mathrm{C}^{2}$ vs. V characteristics at the frequency of $1 \mathrm{MHz}$.

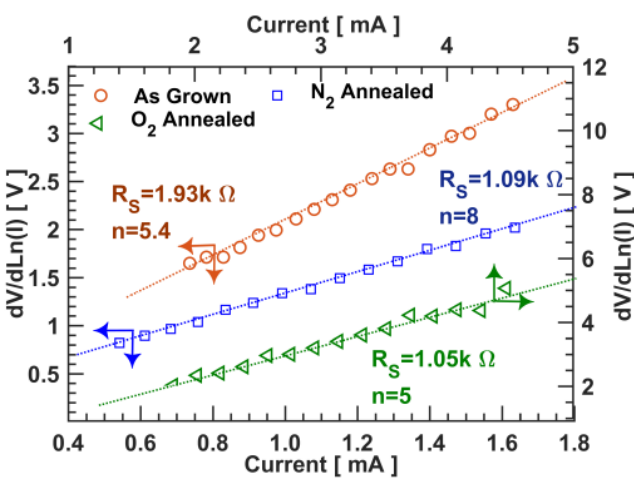

(a)

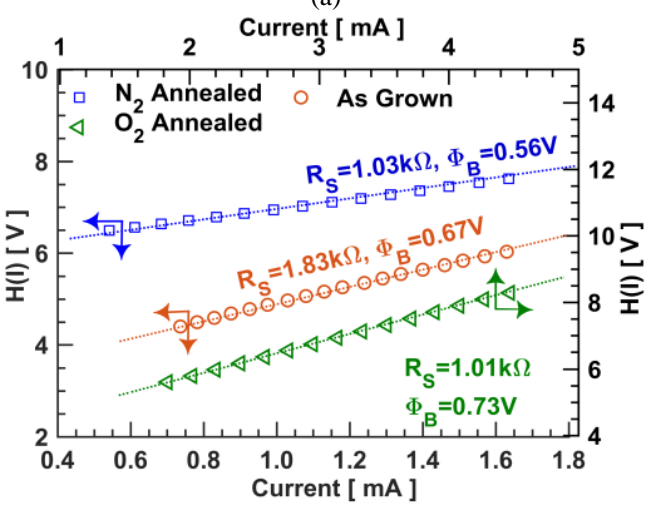

(b)

Fig. 7. (a) dV/dLn(I) vs. forward current characteristics; (b) $H(I)$ vs forward current characteristics. 
TABLE I. EXTRACTED PARAMETERS OF ZNO/SI HETEROJUNCTION DIODES.

\begin{tabular}{|c|c|c|c|c|c|c|c|c|c|}
\hline & \multirow{2}{*}{$\begin{array}{c}\text { Rectification Ratio } \\
\left(\mathbf{I}_{\mathbf{F}} / \mathbf{I}_{\mathbf{R}}\right) \\
@ \pm \mathbf{5 V}\end{array}$} & \multicolumn{3}{|c|}{$\begin{array}{l}\text { Series Resistance (Rs) } \\
(\mathrm{K} \Omega)\end{array}$} & \multicolumn{2}{|c|}{ Ideality factor } & \multicolumn{2}{|c|}{$\begin{array}{l}\text { Barrier height } \\
\text { (V) }\end{array}$} & \multirow[t]{2}{*}{$\begin{array}{c}\text { Carrier Concentration } \\
\left(/ \mathrm{cm}^{3}\right)\end{array}$} \\
\hline & & $\Delta \mathbf{V} / \Delta \mathbf{I}$ & $\begin{array}{c}\mathrm{dV} / \mathrm{d} \ln (\mathrm{I} \\
)\end{array}$ & $\mathbf{H}(\mathbf{I})$ & I-V & $\begin{array}{l}\text { dV/dLn( } \\
\text { I) }\end{array}$ & I-V & $\mathbf{H}(\mathbf{I})$ & \\
\hline As-Grown & 23.1 & 1.44 & 1.93 & 1.83 & 4.40 & 5.4 & 0.75 & 0.56 & $7.8 \times 10^{12}$ \\
\hline $\mathbf{N}_{2}$ Annealed & 40.1 & 0.87 & 1.09 & 1.03 & 3.87 & 8.0 & 0.75 & 0.67 & $1.2 \times 10^{13}$ \\
\hline $\mathrm{O}_{2}$ Annealed & 231.2 & 0.98 & 1.05 & 1.02 & 3.53 & 5.0 & 0.67 & 0.73 & $9.4 \times 10^{12}$ \\
\hline
\end{tabular}

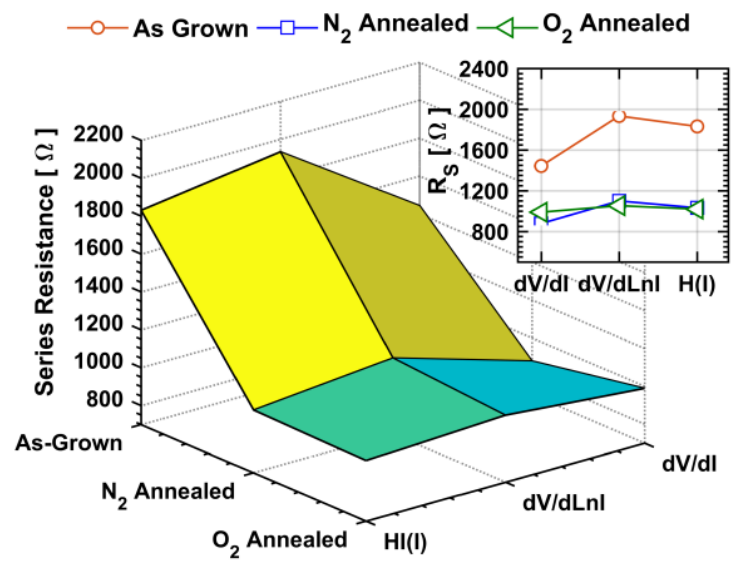

Fig. 8. Comparison of series resistances obtained from conventional method and from Chueng Function.

Low series resistance and improved doping concentrations are the factors responsible for majority carrier's injection under forward bias and improving the rectification factor of $\mathrm{N}_{2}$ and $\mathrm{O}_{2}$ annealed $\mathrm{ZnO} / \mathrm{Si} \mathrm{HJ}$ diodes.

\section{CONCLUSIONS}

The effects of nitrogen and oxygen annealing atmosphere have been investigated on the diode characteristics of $\mathrm{ZnO}$ nanorods/Si heterojunction. The photoluminescence results indicated an improvement in their optical quality after annealing treatment. The ratio of NBE to DLE emissions was greatly increased after the annealing processes. Their heterojunctions diodes exhibited an improvement in rectification factor with decreased series resistances. The series resistances decreased from 1.5 to 1.8 times after annealing. The reported study suggests that $\mathrm{ZnO}$ nanorods annealed in $\mathrm{O}_{2}$ atmosphere may prove to be promising for the realization of more efficient electronic devices, such as solar cells, photodetectors, and heterojunctions.

\section{ACKNOWLEDGMENT}

The authors acknowledge the support and facilities by the Sultan Qaboos Oman IT chair office and Electronic Design Center at the NED University of Engineering and Technology.

\section{CONFLICTS OF INTEREST}

Authors declare that they have no conflict of interest.

\section{REFERENCES}

[1] Ü. Özgür, D. Hofstetter, and H. Morkoç, "ZnO devices and applications: A review of current status and future prospects", Proceedings of the IEEE, vol. 98, no. 7, pp. 1255-1268, Jul. 2010.
DOI: $10.1109 /$ jproc.2010.2044550.

[2] A. Janotti and C. G. Van de Walle, "Fundamentals of zinc oxide as a semiconductor", Reports on Progress in Physics, vol. 72, no. 12, p. 126501, Oct. 2009. DOI: 10.1088/0034-4885/72/12/126501.

[3] N. Al-Hardan, A. Jalar, M. A. Hamid, L. Keng, N. Ahmed, and R Shamsudin, "Corrigendum to "A wide-band UV photodiode based on n-ZnO/p-Si heterojunctions"”, Sensors and Actuators A: Physical, vol. 211, p. 162, May 2014. DOI: 10.1016/j.sna.2014.02.029.

[4] R. Pietruszka et al., "Improved efficiency of $\mathrm{n}-\mathrm{ZnO} / \mathrm{p}-\mathrm{Si}$ based photovoltaic cells by band offset engineering", Solar Energy Materials and Solar Cells, vol. 147, pp. 164-170, Apr. 2016. DOI: 10.1016/j.solmat.2015.12.018.

[5] N. H. Al-Hardan, M. M. Mohd Rashid, A. Abdul Aziz, and N. M Ahmed, "Low power consumption UV sensor based on $\mathrm{n}-\mathrm{ZnO} / \mathrm{p}-\mathrm{Si}$ junctions", Journal of Materials Science: Materials in Electronics, vol. 30, no. 21, pp. 19639-19646, Oct. 2019. DOI: 10.1007/s10854019-02337-2.

[6] N. G. Elfadill, M. R. Hashim, K. M. A. Saron, K. M. Chahrour, M. A. Qaeed, and M. Bououdina, "Ultraviolet-Visible photo-response of $\mathrm{p}$ $\mathrm{Cu} 2 \mathrm{O} / \mathrm{n}-\mathrm{ZnO}$ heterojunction prepared on flexible (PET) substrate", Materials Chemistry and Physics, vol. 156, pp. 54-60, Apr. 2015. DOI: 10.1016/j.matchemphys.2015.02.019.

[7] D. Andriukaitis, R. Anilionis, "Investigation of Etching Process in Nano Structures", Elektronika ir Elektrotechnika, vol. 86, no. 6, pp. 77-80, Jul. 2008

[8] D. Sang et al., "Improved electrical transport properties of an $\mathrm{n}-\mathrm{ZnO}$ nanowire/p-diamond heterojunction", RSC Advances, vol. 8, no. 50, pp. 28804-28809, 2018. DOI: 10.1039/c8ra03546f.

[9] Z. N. Urgessa, S. R. Dobson, K. Talla, D. M. Murape, A. Venter, and J. R. Botha, "Optical and electrical characteristics of $\mathrm{ZnO} / \mathrm{Si}$ heterojunction", Physica B: Condensed Matter, vol. 439, pp. 149152, Apr. 2014. DOI: 10.1016/j.physb.2013.11.001.

[10] V. K. Sahu, P. Misra, R. S. Ajimsha, A. K. Das, and B. Singh, "Effect of growth temperature on diode parameters of $\mathrm{n}-\mathrm{ZnO} / \mathrm{p}-\mathrm{Si}$ heterojuction diodes grown by atomic layer deposition", Materials Science in Semiconductor Processing, vol. 54, pp. 1-5, Nov. 2016. DOI: $10.1016 / \mathrm{j} . \mathrm{mssp} .2016 .06 .006$.

[11] S. Y. Hu, Y. C. Lee, J. W. Lee, J. C. Huang, J. L. Shen, and W. Water, "The structural and optical properties of $\mathrm{ZnO} / \mathrm{Si}$ thin films by RTA treatments", Applied Surface Science, vol. 254, no. 6, pp. 1578-1582, Jan. 2008. DOI: 10.1016/j.apsusc.2007.07.134.

[12] Y. Tu et al., "Control of oxygen vacancies in $\mathrm{ZnO}$ nanorods by annealing and their influence on ZnO/PEDOT: PSS diode behaviour", Journal of Materials Chemistry C, vol. 6, no. 7, pp. 1815-1821, 2018. DOI: $10.1039 / \mathrm{c} 7 \mathrm{tc0} 04284 \mathrm{a}$.

[13] J. D. Hwang and Y. H. Chen, "Effects of pre-annealing conditions on the characteristics of $\mathrm{ZnO}$ nanorods and $\mathrm{ZnO} / \mathrm{p}-\mathrm{Si}$ heterojunction diodes grown through hydrothermal method", Thin Solid Films, vol. 520 , no. 16 , pp. 5294-5299, Jun. 2012. DOI 10.1016/j.tsf.2012.04.015.

[14] S. Ruzgar and M. Caglar, "Fabrication and characterization of solution processed Al/Sn:ZnO/p-Si photodiodes", Materials Science in Semiconductor Processing, vol. 115, article 105076, Aug. 2020. DOI: $10.1016 /$ j.mssp.2020.105076.

[15] R. N. Aljawfi, M. J. Alam, F. Rahman, S. Ahmad, A. Shahee, and S Kumar, "Impact of annealing on the structural and optical properties of $\mathrm{ZnO}$ nanoparticles and tracing the formation of clusters via DFT calculation", Arabian Journal of Chemistry, vol. 13, no. 1, pp. 22072218, Jan. 2020. DOI: 10.1016/j.arabjc.2018.04.006.

[16] S. Tiagulskyi et al., "Highly rectifying heterojunctions formed by annealed $\mathrm{ZnO}$ nanorods on GaN substrates", Nanomaterials, vol. 10, no. 3, p. 508, Mar. 2020. DOI: 10.3390/nano10030508.

[17] J.-D. Hwang, C.-Y. Kung, and Y.-L. Lin, "Non-surface-treated $\mathrm{Au} / \mathrm{ZnO}$ Schottky diodes using pre-annealed hydrothermal or sol-gel seed layer", IEEE Transactions on Nanotechnology, vol. 12, no. 1, pp. 
35-39, Jan. 2013. DOI: 10.1109/tnano.2012.2226188.

[18] E. Kutlu-Narin, P. Narin, A. Yildiz, and S. B. Lisesivdin, "Effects of annealing under different atmospheres on structural and optical properties of USCVD grown $\mathrm{ZnO}$ nanostructures", Materials Science and Engineering: B, vol. 254, article 114506, Apr. 2020. DOI: 10.1016/j.mseb.2020.114506.

[19] J. W. Choi, C. M. Lee, C. H. Park, J. H. Lim, G. C. Park, and J. Joo, "Effect of annealing temperature on morphology and electrical property of hydrothermally-grown $\mathrm{ZnO}$ nanorods/p-Si heterojunction diodes", Journal of Nanoscience and Nanotechnology, vol. 19, no. 3 , pp. 1640-1644, Mar. 2019. DOI: 10.1166/jnn.2019.16186.

[20] $\mathrm{H}$. Alnoor et al., "Influence of $\mathrm{ZnO}$ seed layer precursor molar ratio on the density of interface defects in low temperature aqueous chemically synthesized $\mathrm{ZnO}$ nanorods/GaN light-emitting diodes", Journal of Applied Physics, vol. 119, no. 16, article ID 165702, Apr. 2016. DOI: $10.1063 / 1.4947593$.

[21] S. M. Faraz, W. Shah, N. H. Alvi, O. Nur, and Q. Wahab, "Electrical characterization of $\mathrm{Si} / \mathrm{ZnO}$ nanorod $\mathrm{PN}$ heterojunction diode", Advances in Condensed Matter Physics, vol. 2020, pp. 1-9, Apr. 2020. DOI: $10.1155 / 2020 / 6410573$.

[22] N. H. Alvi, M. Willander, and O. Nur, "The effect of the post-growth annealing on the electroluminescence properties of $\mathrm{n}-\mathrm{ZnO}$ nanorods/p-GaN light emitting diodes", Superlattices and Microstructures, vol. 47, no. 6, pp. 754-761, Jun. 2010. DOI 10.1016/j.spmi.2010.03.002.

[23] G. N. Narayanan, R. S. Ganesh, and A. Karthigeyan, "Effect of annealing temperature on structural, optical and electrical properties of hydrothermal assisted zinc oxide nanorods", Thin Solid Films, vol. 598, pp. 39-45, Jan. 2016. DOI: 10.1016/j.tsf.2015.11.071.

[24] C. H. Ahn, Y. Y. Kim, D. C. Kim, S. K. Mohanta, and H. K. Cho, "A comparative analysis of deep level emission in $\mathrm{ZnO}$ layers deposited by various methods", Journal of Applied Physics, vol. 105, no. 1, article ID 013502, Jan. 2009. DOI: 10.1063/1.3054175.

[25] N. Baydogan, O. Karacasu, and H. Cimenoglu, "Effect of annealing temperature on $\mathrm{ZnO}: \mathrm{Al} / \mathrm{p}-\mathrm{Si}$ heterojunctions", Thin Solid Films, vol. 520, no. 17, pp. 5790-5796, Jun. 2012. DOI 10.1016/j.tsf.2012.04.044

[26] J. Zhang, H. Yang, Q.-1. Zhang, S. Dong, and J. K. Luo, "Bipolar resistive switching characteristics of low temperature grown $\mathrm{ZnO}$ thin films by plasma-enhanced atomic layer deposition", Applied Physics Letters, vol. 102, no. 1, article ID 012113, Jan. 2013. DOI $10.1063 / 1.4774400$.

[27] R. Saha, A. Das, A. Karmakar, and S. Chattopadhyay, "Self-rectifying threshold resistive switching based non-volatile memory of $\mathrm{CBD} / \mathrm{CBD}$ grown vertical $\mathrm{n}-\mathrm{ZnO}$ nanowire/p-Si heterojunction diodes", Advanced Materials Proceedings, vol. 3, no. 4, pp. 298-303, Apr. 2018. DOI: 10.5185/amp.2018/836

[28] D. Saha, A. K. Das, R. S. Ajimsha, P. Misra, and L. M. Kukreja, "Effect of disorder on carrier transport in $\mathrm{ZnO}$ thin films grown by atomic layer deposition at different temperatures", Journal of Applied Physics, vol. 114, no. 4, article ID 043703, Jul. 2013. DOI: $10.1063 / 1.4815941$

[29] C. G. Van de Walle, "Hydrogen as a cause of doping in zinc oxide", Physical Review Letters, vol. 85, no. 5, pp. 1012-1015, Jul. 2000. DOI: 10.1103 /physrevlett.85.1012.

[30] X. H. Huang et al., "Universal photoluminescence evolution of solution-grown $\mathrm{ZnO}$ nanorods with annealing: important role of hydrogen donor", CrystEngComm, vol. 13, no. 23, pp. 7032-7036, 2011. DOI: $10.1039 / \mathrm{c} 1 \mathrm{ce} 05882 \mathrm{~g}$.

[31] S. M. Ali and M. Khan, "Annealing effects on structural, optical and electrical properties of TiO2/FTO heterojunction", Applied Physics A, vol. 126, no. 6, pp. 1-7, May 2020. DOI: 10.1007/s00339-020-036566.

[32] J. Song et al., "The effect of annealing treatment on the performance of bulk heterojunction solar cells with donor and acceptor different weight ratios", Science in China Series G: Physics, Mechanics and Astronomy, vol. 52, no. 10, pp. 1606-1610, Sep. 2009. DOI: 10.1007/s11433-009-0220-0.

[33] Y. Shen, K. Li, N. Majumdar, J. C. Campbell, and M. C. Gupta, "Bulk and contact resistance in P3HT: PCBM heterojunction solar cells", Solar Energy Materials and Solar Cells, vol. 95, no. 8, pp. 23142317, 2011. DOI: 10.1016/j.solmat.2011.03.046.

This article is an open access article distributed under the terms and conditions of the Creative Commons Attribution 4.0 (CC BY 4.0) license (http://creativecommons.org/licenses/by/4.0/) 